\title{
Working through Others - A Qualitative Content Analysis of Nursing Students' Experiences with Malnutrition at One Hospital in Vietnam
}

\author{
Elin Eriksson, $R N, B S c^{1}$, Victoria Ferm, $R N, B S c^{1}$ and Kristina Rosengren, $P h D, R N^{1,2^{*}}$ \\ ${ }^{1}$ Sahlgrenska Academy, Institute of Health and Care Sciences, University of Gothenburg, Sweden \\ ${ }^{2}$ Department of Internal Medicine, Sahlgrenska University Hospital, Mölndal, Sweden
}

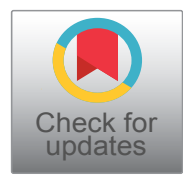

*Corresponding author: Kristina Rosengren, PhD, RN, Associate Professor, Sahlgrenska Academy, Institute of Health and Care Sciences, University of Gothenburg; Department of Internal Medicine, Sahlgrenska University Hospital, Sweden, ORCID iD: 0000-0002-3221-2062

\begin{abstract}
Background: Malnutrition causes problems in Vietnam, including illnesses with physiological and psychological complications. The aim of this study was to describe nursing students' experiences with malnutrition at one hospital in Vietnam.

Methods: Interviews of eight nursing students were performed, and the results were analysed by qualitative content analysis.

Findings: The results are presented in one category (working through others) and three subcategories (awareness of malnutrition, developing family-centered care and developing health promotion).

Conclusion: This study highlights the use of guidelines in collaboration (between staff and patients' relatives) to facilitate early identification and/or prevent malnutrition by improving self-care, as supported through nursing activities using family-centred care as well as teamwork.
\end{abstract}

\section{Keywords}

Family-centered care, Malnutrition, Nursing students, Qualitative content analysis, Teamwork

\section{Introduction}

Research shows that malnutrition causes problems in Vietnam, and the healthcare system lacks screening methods for detecting malnutrition [1,2]. Furthermore, the Western lifestyle has changed Vietnamese food habits by increasing the intake of sugar and fast food, which has resulted in increased obesity, while malnutrition is still a problem [3]. A common way to measure malnutrition is to calculate the BMI (Body Mass Index), but the BMI can be misleading in its definitions of under- and overweight [4]. Vietnam offers two types of nursing education; a 1-2 year nursing program on the diploma level and a 4-4.5 year nursing program on the bachelor level [5], although there is no clear difference in nursing employment with respect to educational background. Therefore, it is interesting to explore nursing students' experience of working on malnutrition to detect and prevent malnutrition, an interface between medicine and nursing.

\section{Background}

Malnutrition is described as starvation connected to chronic and acute illness [6], and defined as a condition characterized by an imbalance or deficiency of calories and nutrients in relation to food intake based on a body's physiological needs. It is often visualized by an underweight person, but could also include one who is overweight [7]. Malnutrition is associated with a lack of carbohydrates, protein or fat, as well as a lack of vitamins and minerals, and the consumption of muscle and fat deposits as a consequence of disease results in weight loss, making prevention important in elderly people with malignant diseases $[8,9]$. Malnutrition also influences physiological conditions such as mobility and mortality, as the intakes of calcium and/or vitamin $D$ influence muscle and bone mass and thereby the risk of fracture. Another aspect is reduced cardiac output, which affects kidney

Citation: Eriksson E, Ferm V, Rosengren K (2019) Working through Others - A Qualitative Content Analysis of Nursing Students' Experiences with Malnutrition at One Hospital in Vietnam. Int Arch Nurs Health Care 5:134. doi.org/10.23937/2469-5823/1510134

Accepted: October 03, 2019: Published: October 05, 2019

Copyright: (C) 2019 Eriksson E, et al. This is an open-access article distributed under the terms of the Creative Commons Attribution License, which permits unrestricted use, distribution, and reproduction in any medium, provided the original author and source are credited. 
function via decreased blood flow and glomerular filtration. Malnutrition also influences endocrine functions through decreased levels of thyroid hormones, testosterone, and oestrogen and reduced insulin secretion, as well as the diaphragm and respiratory muscles with limitations placed on coughing. Gastrointestinal side effects affect the blood flow, resulting in reduced amounts of enzymes that can break down food, which influences lactose tolerance and produces symptoms such as diarrhea [10]. Therefore, it is important to prevent and treat risk factors for malnutrition by improving health professionals' knowledge to promote a high quality of healthcare and rehabilitation [11].

Malnutrition also affects the immune system and increases the risk of bacterial infection, which is why wound healing is reduced [4]. Research $[4,8,10]$ has shown that risk factors such as infection are more prevalent in countries with limited resources due to a combination of poverty, social isolation and abuse, for example, apathy and depression. The connection between food and well-being varies in relation to patients' individual needs and thoughts; a health professional's awareness of issues related to the prevention of malnutrition is an important tool to mitigate the negative effects as the number of hospital stays increases [11]. Moreover, research shows that the nursing practice as applied to malnutrition rarely involves the active participation of the patient, and responsibility from the nurse's perspective is needed to identify and coordinate the patient's nutrition issues. The nurses' role is to support patients with problems; for example, they can help patients with dysphagia to sit in an upright position and use techniques to facilitate swallowing. Furthermore, difficulties with chewing due to feeding issues need support by nurses for a healthy recovery, for example, a quiet and social meal environment [12]. However, nurses are often unfamiliar with patients' nutritional status and whether patients eat independently or not $[11,12]$.

One aspect that distinguishes Vietnamese from other nations' healthcare organizations, for example, those of Sweden, is a lack of food services at the hospital and health insurance, which is why a patient's family organizes foodservice when they are hospitalized [1,2]. Therefore, Jefferies, et al. [11] emphasizes that nurses must get involved in the diet and nutrition provided by relatives to improve health food service at the hospital to improve recovery and decrease malnutrition. The government of Vietnam developed a national nutrition agenda to improve the population's health status to prevent, for example, hospital-related malnutrition [1,2], a cost-effective way to improve healthcare [4].

Vietnam's history of war ended in 1975, resulting in a change from emergency to general care; howev- er, there are varieties of nursing skills that are not provided in the nursing education. As physicians had taught nurses, the nursing education had focused on medicine [5], and moreover, the nursing education provided at universities was separate from hospitals. Therefore, the goal of the VNA (Vietnam Nurses Association) is to improve the quality of care for patients by creating standardized plans for professional practice, regardless of which hospital a nurse is working at. In addition, the government of Vietnam decided in 2006 that as of 2016, those in the nursing profession would be licensed, i.e., as registered nurses 13]. Research [1,2,3,8-12] has shown that malnutrition continues to cause problems in Vietnam, which is why nurses have a significant role in promoting a high quality of care regarding a healthy nutrition status in hospitals in Vietnam. One way to reduce malnutrition is using Orem's [14] theory of self-care based on three strategies: performing self-care independently, receiving supported self-care by nurses providing guidance or training, or having the nurses/healthcare system carry out all activities due to a patient's complete lack of ability to provide self-care [15]. Therefore, this study intends to study nursing activities related to nursing education, with the aim of describing nursing students' experiences with malnutrition at one hospital in Vietnam.

\section{Method}

\section{Settings}

This study was conducted at Hanoi Medical University [16]; one of the oldest and leading medical universities in Vietnam that strives to reach excellence in healthcare professional training, in research, and in applied science and technology. The Nursing Departments offer a bachelor's degree in nursing within two nursing programs: National nursing programs in Vietnamese (4 years) and Advanced nursing programs in English (4.5 years), developed together with California State University. The Ministry of Health in Vietnam [13] provided assistance for an education intervention implemented by the Ministry of Health and led by Hanoi Medical University. In addition, TRAC (Training and Research Academic Centre) was established to improve cooperation between universities (Gothenburg University is one of these) and health institutions in Vietnam to assess the health situation in Vietnam. The average life expectancy in Vietnam in the year 2009 was 75.6 years for females and 70.2 years for males, and the most common diseases were tuberculosis, malaria, cancer, and chronic respiratory and cardiovascular diseases [17].

\section{Design}

A qualitative method was used together with an inductive approach to understand nursing students' voices, views and thoughts regarding malnutrition 
Table 1: Example of analysis of content into subcategories that formed a category.

\begin{tabular}{|c|c|c|c|c|}
\hline Meaning unit & Condensed content & Coding & Subcategory & Category \\
\hline $\begin{array}{l}\text { "Sometimes the nurses the can get them advice but } \\
\text { it's not like daily routine or not like a procedure they } \\
\text { have to do with every patient sometimes they think } \\
\text { about that they do it's not like on document they } \\
\text { have to say or have to advice the patient, they do } \\
\text { what they want or they do what they are think about } \\
\text { that yeah". }\end{array}$ & $\begin{array}{l}\text { not like daily routine or } \\
\text { procedure they do, it's not } \\
\text { like on document or advice } \\
\text { patient, do what they think }\end{array}$ & Routines & $\begin{array}{l}\text { Awareness of } \\
\text { malnutrition }\end{array}$ & $\begin{array}{l}\text { Working } \\
\text { through } \\
\text { others }\end{array}$ \\
\hline $\begin{array}{l}\text { "Traditional hospital it's so crowded with patients so } \\
\text { that doctor and nurses cannot focus on details of } \\
\text { patient, so it's difficult for us to take care of like each } \\
\text { patient and difficult for us to evaluate best condition } \\
\text { for the patient. So, it is quite difficult if a lot of } \\
\text { patients get malnutrition, we don't have time to take } \\
\text { care of them totally". }\end{array}$ & $\begin{array}{l}\text { hospital crowded with } \\
\text { patients, staff cannot } \\
\text { focus, difficult take care } \\
\text { each patient, lot of patients } \\
\text { get malnutrition, don't have } \\
\text { time }\end{array}$ & Overcrowded & $\begin{array}{l}\text { Developing } \\
\text { family-centered } \\
\text { care }\end{array}$ & $\begin{array}{l}\text { Working } \\
\text { through } \\
\text { others }\end{array}$ \\
\hline $\begin{array}{l}\text { "The education for the patient in the rural area is } \\
\text { not very good. We have a community; we have a } \\
\text { programme to take this problem closer to people in } \\
\text { the rural area but actually it's not working very well } \\
\text { and it needs to improve in the future". }\end{array}$ & $\begin{array}{l}\text { education patient rural } \\
\text { area not good, programme } \\
\text { closer to people, not } \\
\text { working well, needs } \\
\text { improvement }\end{array}$ & $\begin{array}{l}\text { Quality } \\
\text { improvement }\end{array}$ & $\begin{array}{l}\text { Developing } \\
\text { health } \\
\text { promotion }\end{array}$ & $\begin{array}{l}\text { Working } \\
\text { through } \\
\text { others }\end{array}$ \\
\hline
\end{tabular}

The findings are illustrated with quotes.

in Vietnam. A content analysis illustrates the use of several concepts related to the research procedures to achieve trustworthiness: credibility, dependability and transferability $[18,19]$. A qualitative research design that relies on trustworthiness, transparency, verification, and reflexivity, and that is "information-driven", can be helpful when developing insightful and artful interpretations within nursing education processes [20].

\section{Data collection}

A convenient small sample related to qualitative methods was used [20]. The inclusion criteria for participation were nursing students over the age of 18 , in their last year of education (4 year) at the bachelor level for general nursing at the Hanoi Medical University, with experience with malnutrition, and the ability to understand and speak English. An international coordinator at the Nursing Department, Hanoi Medical University sent out an inquiry, and students who were interested in participating called two of the authors (EE, VF); the first eight nursing students were included. Ethical guidelines for human and social research were considered throughout the study [21]. Data were collected in October 2016, all participants $(n=8)$ were informed about the aim and study procedures, and confidentiality was assured. The interviews started with background questions including age, education and experiences in healthcare. Data collection focused on five perspectives: protective factors, complications regarding under- and overweight and malnutrition, the nurse's role, skills related to malnutrition, and future aspects. The interviews started with "If I say malnutrition, what are your thoughts about this area?" Based on the answers, related questions were asked. Examples of situations such as positive and negative aspects of malnutrition were explored, and clarifications and further elaborations were made. The interviews lasted between $17-$ 34 minutes and were performed individually by two of the authors (EE, VF). All interviews were recorded and then transcribed verbatim. The participants were female nursing students on the bachelor level aged between 19 to 22 years.

\section{Data analysis}

The interviews were analysed using manifest qualitative content analysis $[18,19]$ to interpret the meaning from the content of the data to address trustworthiness [20] with examples drawn from the area of the nursing students' experiences with malnutrition. The written words were the basis for the analysis that was performed in the following steps (Table 1): 1. Transcripts were read and re-read to obtain an understanding of and familiarity with the text; 2 . Meaning units (words, sentences or paragraphs) corresponding to the content areas were selected using an inductive approach concerning (a) routines and (b) relatives' involvement; 3 . Each meaning unit was condensed into a description of its content and labelled with one of 72 codes; 4 . Subcategories were identified and grouped related to codes; and 5. One category was identified, i.e., working through others, and three subcategories were grouped, i.e., awareness of malnutrition, developing family-centered care and developing health promotion.

\section{Ethical considerations}

Ethical approval and permission for the study were obtained from the director of the Nursing Department, Hanoi Medical University. No ethical approval was needed due to Swedish rules and guide- 


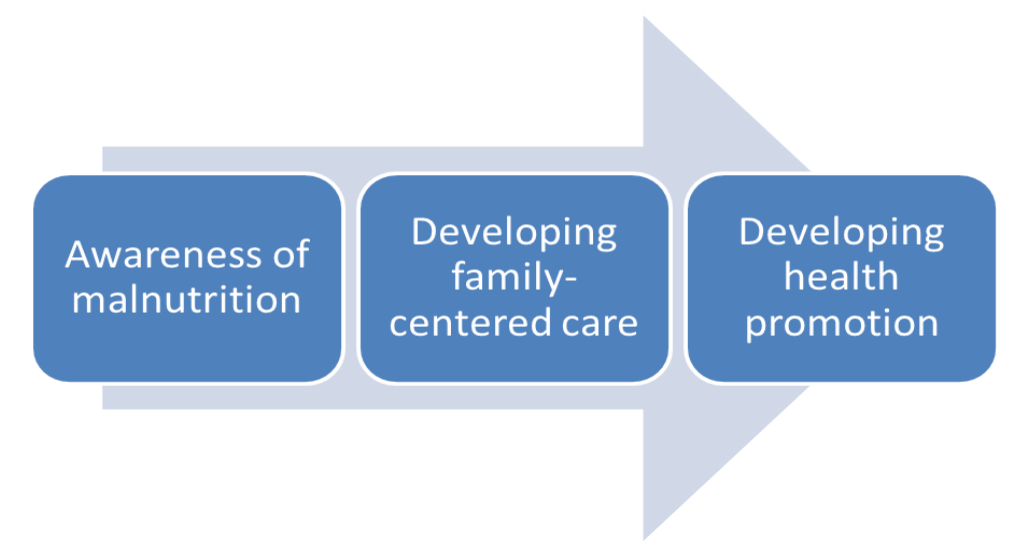

Figure 1: The category and subcategories generated in the results.

lines regarding a student's thesis and/or quality improvement that have no negative effects for the participants [21,22]. However, ethical guidelines for human and social research were followed throughout the study. Respect for the individual student was a main concern during the study. All students were informed about voluntary participation and their right to withdraw at any time and that their answers would be kept confidential. The results are described in categories without identifications. Respect for the informants' integrity and autonomy was thereby shown [21].

\section{Results}

The results formed one category, "Working through others", and three subcategories, "Developing awareness about malnutrition", "Developing family-centered care" and "Developing health promotion". Collaboration between the nurse's knowledge of malnutrition and relatives' meal services in the hospital were described as significant to create a common understanding and agreement regarding nutrition issues and health and/or well-being. The categories are presented in Figure 1.

\section{Working through others}

The category of working through others is described as nursing activities to facilitate awareness of malnutrition, family-centered care and health promotion. The informants highlighted that knowledge of malnutrition in Vietnam is low, both in the population and among nurses, which is why education is needed to improve the healthcare of malnourished patients. In addition, healthcare in Vietnam is dependent on family members providing basic care (washing, dressing, etc.) and meal services (buying, preparing). To improve the quality of care, the nurses provide advice and support for obtaining nutritious food, but the relatives and patient decide what type of food is to be purchased and eaten in the hospital, therefore, the nurses have a limited input into patients' nutritional intake. The nurses are expected to follow physicians' directives and act as medical assistants, but the informants highlight the need for increased nurse initiative to decrease the number of malnourished patients.

\section{Developing awareness about malnutrition}

The subcategory of developing awareness about malnutrition considers the limited knowledge (theoretical, practical) regarding malnutrition in relation to education in nursing as well as among patients and their families. Nursing students stress that a lack of awareness regarding nutrition among the population, especially in rural areas, causes malnutrition to be widespread in Vietnam. The informants describe ignorance among the involved actors (patients, relatives, staff) on how to achieve a balanced healthy diet (fat, protein, vitamins and carbohydrates) in everyday life situations. Therefore, the nursing students highlight that nurses have a significant role in supporting healthy nutrition through nursing activities to improve knowledge and facilitate tools for patients and relatives. They argue that malnutrition is common in the paediatric and geriatric specialties, which is why nursing education needs to focus on the types of measurements that could be used to recognize a malnourished patient and how nurses could establish care plans that consider malnutrition. The nursing students stress that malnutrition contributes to difficulties in combating illness and increases the risk of infection, which results in increased hospital stays as well as psychological issues such as slower reactions and increased stress in daily life situations.

The informants highlight the shortcomings of documentation in medical records, though medical procedures and drugs dominate the information. Moreover, nursing students' stress that the evaluation of malnutrition is viewed as a nutritionist's responsibility, not a nurse's, which is illustrated as:

I think in Vietnam; I think the nurse is not doing the care for the nutrition for the patient. So, I think the nurse really requires attention to nutrition for the patient, like they have to take a course to study nutrition for the patient. (thinking), and I think they have to rec- 
ognize that malnutrition care is their responsibility, not just as for a test or for the nutritionist... (Informant 3)

The informants described that, for patients with difficulties in swallowing, the nurses use liquids and foods with soft textures as well as smaller portions and a small spoon to facilitate the relative's meal services. They stress that difficulty in swallowing needs investigation, for example, for underlying diseases. For example, physicians could prescribe a nasogastric tube or parenteral nutrition as well as regular food schedules, which is common in intensive care units. In addition, the nursing students highlight that nursing activities as teaching and training regarding swallowing in combination with healthy food improve the quality of care. They describe that nurses calculate the BMI to diagnose malnutrition, but they were unclear if an overweight person may also suffer from malnutrition, and they expressed uncertainty of how malnutrition could be detected. Some highlight that vitamins are significant aspects, while others argue that blood sampling could identify malnutrition. However, the informants described that the overweight in Vietnam had increased risk due to high sugar consumption as well as the intake of fast and fried foods. In addition, the nursing students stress that the nursing profession has a low status in Vietnam due to the different types of nursing education (diploma, bachelor), which is why barriers such as mistrust could occur. The variation of nursing knowledge regarding malnutrition was described as:

We can have more knowledge about malnutrition, and in clinical, they estimate that "every nurse is the same", which provides very, very great barriers for us to provide advice to the patients because this nurse (diploma level) does not have advice for the patient... or does not have enough knowledge, because she is a short-term educated nurse. I hate it in Vietnam; it is different in other countries, I know, like in Sweden or Denmark. So they (diploma nurses) are not active and creative in their own work, and they do not support nutrition for patients in a positive way..... but we are bachelors in nursing, we have more knowledge so we can advise patients, but people believe that we do not have enough knowledge to do it, and we are like assistants to doctors, but we are not assistants. I think it is like the head bone, the doctor is like horses, and whatever they say, we have to do it (Informant 5)

\section{Developing family-centered care}

The subcategory developing family-centered care considers a family's social situation as affected by hospital admissions, variations of knowledge regarding nutrition aspects and economic perspectives. According to the informants, there are two types of hospitals in Vietnam, traditional hospitals (most common) with lower standards, in which the family takes care of all meal services, and international hospitals, in which nu- tritionists are employed and meal services are offered. Nurses who work in traditional hospitals have limited possibilities to influence food intake regarding nutritional aspects, while family members are a natural part of Vietnamese healthcare, providing meal services and personal hygiene services. Nurses support patients with nasogastric tubes, but otherwise, the nurse has only an advisory and instructional role for the nutritional aspects, as the relatives are in charge.

A hospital stay affects the whole family's social situation by requiring that they rent additional accommodations near the hospital to care for their loved one. Sometimes families need to employ an external person to take care of a patient at a hospital. The informants note that these additional costs affect the family's income, causing cheaper groceries to be chosen without high nutritional value, which is illustrated as:

Normally, family members will feed them. Nurses don't need to feed them, but for ICU department, nurse will feed them. And they have food schedule, but some hospitals don't use them totally. Normally, nurses are in charge, and they tell the family member what and how they can buy food, and relatives will go out and buy this kind of food. If the doctor or nurse don't say anything about food, they will automatically buy the food they love to eat (Informant 7).

Furthermore, the informants stress that the relatives are ignorant or oblivious about what types of foods are appropriate to be served in a hospital:

Sometimes you see that their meal does not contain enough essential nutrition; just rice, meat or something, a little bit too limited. But I think they (patients) need plenty of nutrition, plenty of food. It's not like a big problem but still a problem because they don't think, "that nutrition is essential, or vitamin C, so I have to take it, I need vitamin C", no, they don't know which food is rich in nutrition and which not (Informant 6).

The informants have an ambition to establish an individual meal plan for each patient, but the hospitals are overcrowded with a high number of patients and family members at the ward level, which limits their ability to focus on meal situations to evaluate patients' conditions.

\section{Developing health promotion}

The subcategory developing health promotion considers families' socioeconomic status as it affects the patient's responsibility for healthy life and selfcare. Nursing students highlight their willingness to contribute to the best possible care for patients with malnutrition, but health problems occur during illness that affect the nurses' ability to work with health promotion. The informants highlight that less educated people with limited money in rural areas far away from health centers choose unhealthy food, which causes ill health from malnutrition. Obesity and malnutrition 
are described as a double social burden. Obesity does not automatically lead to reduced malnutrition, but instead increases it. The informants also stress that people in rural areas do not take malnutrition seriously until they are admitted to the hospital due to their visibly limited health status. Moreover, nursing students describe that a knowledge-based program is used to highlight problems with malnutrition in the rural areas, but improvement is needed. One informant describes it as:

As a nurse, I really want to work in the community, if we fight this in the community, I'm sure that the risk of malnutrition will be limited. I want to improve knowledge about malnutrition and how to control it and how to care for a patient with malnutrition in the hospital and also in the community. For example, for a patient who is overweight or underweight in the hospital together with a disease, I don't want to just give them some advice and let them go home without doing anything. I want to make a long-term follow up for control over a longer period of time (Informant 8)

In addition, the informants emphasize the patient's responsibility to avoid and/or address malnutrition and highlight the nurse's role to support and motivate patients regarding healthy nutrition in relation to patient' compliance:

So, I think that the self-perspective and self-care is very important. Especially in Vietnam, we don't spend enough time with the patient, so patient self-care is very important for them, because it's their body. When they are aware of that information and malnutrition, they can intake more (Informant 6)

The nursing students note that health promotion is easier to perform when the patients are motivated to maintain their health through better self-care. The informants highlight the nurses' role to support and encourage regular meals containing protein as well as carbohydrates to prevent missing breakfast, lunch or other meals. Teaching based on the patient's life situation and medical history based on evidence regarding malnutrition is stressed as one tool for nurses to develop health promotion though self-care. The nursing students argue that young people manage self-care in a better way, as they are motivated to keep in shape. An obstacle for health promotion that is described by the informants is that Vietnamese health insurance only covers malnutrition if a patient has more than one disease/diagnosis, which is why patients wait too long for help or treatment addressing malnutrition.

\section{Discussion}

The aim of describing nursing students' experience with malnutrition within hospitals in Vietnam was achieved. The results of working through others include providing awareness about malnutrition and developing family-centered care as well as developing health promotion in home health care, which could be viewed in relation to self-care [15]. However, sometimes patients need support from family members and/or health professionals. Nursing students, as future nurses, require a health care system as well as insurance systems that facilitate nursing interventions. Therefore, the Ministry of Health in Vietnam [13] needs to improve the insurance system (single disease instead of multi-disease) to discover malnutrition in an early state as well as offer meal services in the hospital to treat malnutrition. Moreover, nursing education on the bachelor level has improved nurses' knowledge [23], making nursing more than merely assistant work to physicians. It is thus important to increase the nurses' creative and preventive work in Vietnamese hospitals as well as in the community. One obstacle is the hierarchical healthcare system in which nurses follow directives without critical thinking. In addition, a lack of cooperation among health professionals leads to adverse consequences in healthcare [24]. However, the WHO's [25] framework regarding interprofessional collaboration facilitates good relationships and communication. A relationship based on respect and shared objectives for healthcare are key factors for problem solving. A similar vision within health professional educational programs in Vietnam facilitates collaboration that reduces healthcare-associated infections and abnormalities, where malnutrition is a well-known risk factor of various diseases that affect a broad spectrum of patients in Vietnam. The quality of healthcare and patient safety is closely linked to interprofessional collaboration and the use of different skills, for example, in home health care.

Malnutrition is not always well documented in medical records, medical rounds or handovers due to shifts of staff members. For example, the Swedish healthcare organizations have blurred the boundaries between nurses and assistant nurses, although they are responsible for assessing and monitoring patients' nutritional measures [26]. Nursing students describe varying degrees of documentation of nutritional measures, and why nurses need more knowledge about malnutrition in nursing education as well as time and space to use this knowledge in hospital settings. Furthermore, nurses need communication skills for working through others, such as family members and patients by using family-centred care to decrease malnutrition in Vietnam, regarding eating habits and meal service [1]. A path for improvement is a nice dining room where patients and families could be together instead of food served in bed in an overcrowded room without integrity at meals [11].

Family centered care in Vietnam [1] includes traditions in relation to meal services at the hospital together with general caring such as hygiene (shower, bath) 
and dressing (clothes). This could be viewed as a financial burden [4], which is why nurses' support is needed to decrease malnutrition in Vietnam. Vietnam's government nutrition agenda is another tool to decrease malnutrition, but many nursing students lack this information [2]. Therefore, there is a need for improvement in education for nurses, creating guidelines for nutrition issues related to physiological and psychological risk factors [10] to improve self-care regarding a caring environment [15]. Routines affect the nurse's opportunity to educate patients regarding self-care due to eating habits using Mini Nutritional Assessment, MNA [27]. Moreover, nurses with extensive work experience use their clinical expertise to perform assessments of malnourished patients' care needs $[1,26]$, using care plans that relatives can follow. Furthermore, the variation of nursing education ( 2 to 4.5 years) is a foundation for this knowledge gap between nurses, which influences the quality of the nurse's support and education among patients and family members regarding malnutrition [5]. In addition, the nursing student's experiences of mistrust regarding their skills requires the reorganization of healthcare to facilitate a high quality of care.

\section{Limitations}

The limitation of the study is that it was carried out at one school of nursing in one country, Vietnam. The small sample limits the ability to generalize to other settings. However, the trustworthiness of the results was ensured through a scientific systematic analysis using manifest qualitative content analysis, a well-documented methodology $[18,19]$. The study's validity, though, might be discussed due to the data collection procedure involving a limited number of interviews $(n=8)$. The variations in the nursing students' experiences of malnutrition and English skills could also be a limitation. Moreover, Sweden and Vietnam differ regarding the social structure, education and healthcare systems, which must be taken into consideration regarding the transferability of the current study, which is why further studies are needed to develop knowledge. For example, quantitative research that includes a larger number of informants could contribute to increased knowledge regarding nursing and malnutrition.

\section{Conclusion}

The current study has contributed to an understanding of nursing students' experiences with malnutrition in Vietnam by showing significant examples of working through others to reduce the risk and consequences of malnutrition. Motivation for self-care is not a prioritized task in Vietnam, which is why nursing students have to be prepared to face malnutrition during nursing education (theoretical and clinical), although malnutrition is common worldwide (hospital care, home health care). Patient safety could be improved by simulation in nursing education, where the nursing student's theoretical knowledge is visualized in practical settings. Moreover, a lack of financial resources, organizational structures and treatment, as well as a focus on reducing symptoms instead of preventing malnutrition in home health care, are risk factors that increase malnutrition. Therefore, this study highlights the development of national guidelines that support self-care and teamwork (staff, patient, relatives) to prevent or facilitate the early identification and/or treatment of malnutrition among the Vietnamese population by using family-centred care.

\section{Conflicts of Interest}

The authors declared no potential conflicts of interest with respect to the research, authorship or publication of this article.

\section{Acknowledgements}

We thank the nursing students at the Hanoi Medical University who participated in the study and the University of Gothenburg Centre for Person-centered Care (GPCC), Sahlgrenska Academy, University of Gothenburg, Sweden.

\section{References}

1. Hagström A, Florén H, Rosengren K (2019) Family-centred care - A tool to decrease malnutrition among children in Vietnam. Int Arch Nurs Health Care 5: 116.

2. Hanna KL, Glen KD, Lau BT, Tran CQ, Truong NT, et al. (2016) Relationship between malnutrition and selected risk factors in two hospitals in Vietnam. Nutr Diet 73: 59-66.

3. Khan NC, Khoi HH (2008) Double burden of malnutrition: The Vietnamese perspective. Asia Pac J Clin Nutr 17: 116118.

4. MacAllan D (2009) Infection and malnutrition. Medicine 37: 525-528.

5. Harvey T, Calleja P, Thi D (2013) Improving access to quality clinical nurse teaching - A partnership between Australia and Vietnam. Nurse Educ Today 33: 671-676.

6. Mauldin K, O'Leary-Kelley C (2015) New guidelines for assessment of malnutrition in adults: Obese critically ill patients. Crit Care Nurse 35: 24-30.

7. Viet Nam - Food and nutrition security profiles.

8. Lochs H, Dervenis C (2003) Malnutrition - The ignored risk factor. Dig Dis 21: 196-197.

9. Saunders J, Smith T (2010) Malnutrition: Causes and consequences. Clin Med (Lond) 10: 624-627.

10. Saunders J, Smith T, Stroud M (2011) Malnutrition and undernutrition. Medicine 39: 45-50.

11. Jefferies D, Johnson M, Ravens $J$ (2011) Nurturing and nourishing: The nurses' role in nutritional care. J Clin Nurs 20: $317-330$.

12. Perry L, Hamilton S, Williams J, Jones S (2013) Nursing interventions for improving nutritional status and outcomes of stroke patients: Descriptive reviews of processes and outcomes. Worldviews Evid Based Nurs 10: 17-40.

13. https://mcnv.org/

14. Orem DE, Taylor SG (2011) Reflections on nursing practice 
science: The nature, the structure, and the foundation of nursing sciences. Nurs Sci Q 24: 35-41.

15. Taylor SG, Renpenning K (2011) Self-care science, nursing theory and evidence-based practice. Springer Publishing Company, New York.

16. Hanoi Medical University (2007) History of Hanoi Medical University.

17. WHO (2017) Nutrition.

18. Graneheim UH, Lundman B (2004) Qualitative content analysis in nursing research: Concepts, procedures and measures to achieve trustworthiness. Nurse Educ Today 24: 105-112.

19. Graneheim UH, Lindgren BM, Lundman B (2017) Methodological challenges in qualitative content analysis: A discussion paper. Nurse Educ Today 56: 29-34.

20. Polit D, Beck CT (2017) Nursing research: Generating and assessing evidence for nursing practice. Wolters Kluwer Health/Lippincott Williams \& Wilkins, Philadelphia.
21. Codex (2019) Rules \& guidelines for research. The humanities and social sciences.

22. https://www.riksdagen.se/sv/dokument-lagar/dokument/ svensk-forfattningssamling/halso--och-sjukvardslag_sfs2017-30

23. Aase I, Aase K, Dieckmann P (2013) Teaching interprofessional teamwork in medical and nursing education in Norway: A content analysis. J Interprof Care 27: 238-245.

24. Havens DS, Vasey J, Gittell JH, Lin WT (2010) Relational coordination among nurses and other providers: Impact on the quality of patient care. J Nurs Manag 18: 926-937.

25. WHO (2010) Framework for action on interprofessional education and collaborative practice.

26. Bååth C, Wilde Larsson B, Idvall E, Lord Hall ML (2012) Assessments of patients' pain, nutrition and skin in clinical practice: Registered and enrolled nurses' perceptions. Int J Orthop Trauma Nurs 16: 3-12.

27. Nestlé (2009) Mini nutritional assessment. 